\title{
MAATALOUSYRITTÄJIEN JA LOMITTAJIEN ALTISTUMINEN VARASTOPUNKEILLE MAATILOILLA: SIKALAT, KANALAT JA
}

\section{TALLIT}

\author{
Sirpa Pennanen \\ Kuopion aluetyöterveyslaitos, Ympäristömikrobiologian laboratorio, PL 93, 70701 Kuopio \\ Sirpa.Pennanen@ttl.fi
}

Huonepölypunkkien ja allergioiden välinen yhteys on tunnettu jo kauan. Kosteusvaurioiden yleistyessä sekä kodeissa että työpaikoilla, on havaittu myös varastopunkkien merkitys allergioiden aiheuttajina. Suomalaisen ammattitautitilaston mukaan vuosittain punkkien aiheuttaman ammattitaudin saa 50-150 työntekijää. Työpaikkojen punkeista tiedetään kuitenkin erittäin vähän. Punkkien esiintyminen runsain määrin työpaikalla voi aiheuttaa työntekijöille oireilua, ja pahimmassa tapauksessa ammattitaudin.

Kuopion aluetyöterveyslaitoksella ympäristömikrobiologian laboratoriossa olemme tutkineet maatiloilla työskentelevien ihmisten altistumista ja herkistymistä punkeille. Halusimme selvittää, mitä varastopunkkilajeja valituissa työympäristöissä esiintyy, mitkä ovat niiden runsaussuhteet ja vaihtelevatko lajisto tai punkkimäärät vuodenaikojen mukaan. Samoin tutkimme punkkien kulkeutumista maatalousympäristössä. Selvitimme myös tutkimukseen valittujen työntekijöiden oireilua, allergiasairauksia ja mahdollista herkistymistä varastopunkeille.

Tutkimuksessa oli mukana yhdeksän maatilaa (kolme sikalaa, kanalaa ja tallia) ja 23 maatalouslomittajaa. Punkkeja löytyi kaikista tutkituista työympäristöistä. Tuotantoeläimen pieni koko (kana) ja pölyisyys liittyivät suuriin punkkimääriin. Noin $40 \%$ maatalouden näytteistä sisälsi enemmän punkkeja kuin arvioitu herkistymisraja-arvo (100 punkkia grammassa pölyä) on. Lajistollisesti kaikki nyt tutkimamme kohteet olivat samankaltaisia, näytteistä löytyi pääasiassa varastopunkkeja. Pyroglyphidae-heimon punkkeja (huonepölypunkkien heimo) löytyi merkittävästi vain kanaloista. Punkkien esiintyminen maatalouden kohteissa vaihteli vuodenajoittain. Eläintiloista punkkeja löytyi eniten syksyllä ja talvella, kun taas kesä oli kotien punkkirikkainta aikaa. Vaihtelu johtunee ko. tiloissa vallitsevista ja vuodenajan mukaan vaihtelevista kosteus- ja lämpötilaolosuhteista. Punkit myös kulkeutuivat eläintiloista koteihin. Erityisesti Acaridae- ja Tarsonemidae- heimojen punkkeja löytyi yhtäaikaa sekä eläintiloista että kotoa.

Oirekyselyn perusteella lomittajat kärsivät iho-oireista enemmän kuin viljelijät. Tutkittujen sikaloiden ja kanaloiden työntekijät kärsivät hengitystieoireista enemmän kuin tallien työntekijät. Lääkärin toteamia allergiasairauksia oli yleensä viljelijöillä saman verran kuin väestössä keskimäärin ja lomittajilla hiukan tavanomaista enemmän. Lomittajista oli $17 \%$ herkistynyt ainakin yhdelle punkille.

Riski altistua ja herkistyä punkeille on ilmeinen maatalouden parissa, joten altistumisen ehkäisy on tärkeää. Punkkien määrän voi minimoida tehokkalla siivouksella ja muuttamalla olosuhteet punkeille epäsuotuisaksi toisin sanoen pitämällä ilman lämpötila ja kosteus riittävän alhaisina. Riittävä ilmanvaihto ja oikeanlainen suojautuminen ovat tärkeitä keinoja altistumisen vähentämiseksi.

Avainsanat: varastopunkki, maatilat, altistuminen 


\section{Johdanto}

Siitä asti kun Dermatophagoides spp. punkkien ja huonepölyallergian välinen yhteys todettiin (Voorhorst ym. 1964), on yhä enemmän julkaistu tietoa huonepölypunkkien ja allergioiden yhteydestä (mm. Platts-Mills ja Chapman 1987, Platts-Mills ja de Weck 1989, Platts-Mills ym. 1992 ja 1997). Vastaavasti varastopunkit on todettu erityisesti karjatalouden, viljanviljelyn ja sen liitännäisalojen allergiaa aiheuttaviksi lajeiksi (mm. van Hage-Hamsten ym. 1987, Cuthbert 1990, Iversen ym. 1990, Patussi ym. 1994, Iversen ja Hallas 1995, Kronqvist ym. 1999, Müsken ym. 2000). Maatalouden muilla aloilla mm. siipikarjan loispunkit, kuten Dermanyssus gallinae ja Ornithonyssus sylviarum, ovat todistetusti allergioiden aiheuttajia (Lutsky ym. 1984, Baselga ym. 1996).

\section{Aineisto ja menetelmät}

Tutkimushenkilöille teetettiin oirekysely, joka saatiin 121 viljelijältä ja 166 lomittajalta.

Pölynäytteiden ottoon valittiin kolme sikalaa, kanalaa ja tallia sekä 23 maatalouslomittajaa. Maatalousyrittäjien kohdalla kohteena oli työpaikka, työvaatetus ja asunto, ja maatalouslomittajien kohdalla vaatetus, kulkuväline ja asunto. Pölynäytteistä laskettiin ja tunnistettiin punkit. Kaikilta tutkimushenkilöiltä otettiin verinäyte punkkispesifisten IgE-vasta-aineiden määrittämiseksi.

\section{Tulokset}

Tiloilla käytiin neljästi, jotta saataisiin selville mahdollinen vuodenaikaisvaihtelu sekä punkkimäärissä että lajistossa. Lähes kaikista näytteistä löytyi punkkeja (84-91\%). Kun kaikkien näytteiden mediaanit laskettiin vuodenajoittain eli yhdistettiin sikala-, kanala- ja tallinäytteet sekä näiden sisällä koti-, työvaatetus- ja eläintilanäytteet, saatiin näkyviin pieni vuodenaikaisvaihtelu. Kesällä tämän mukaan löytyi eniten punkkeja ja keväällä vähiten (Kuva 1).

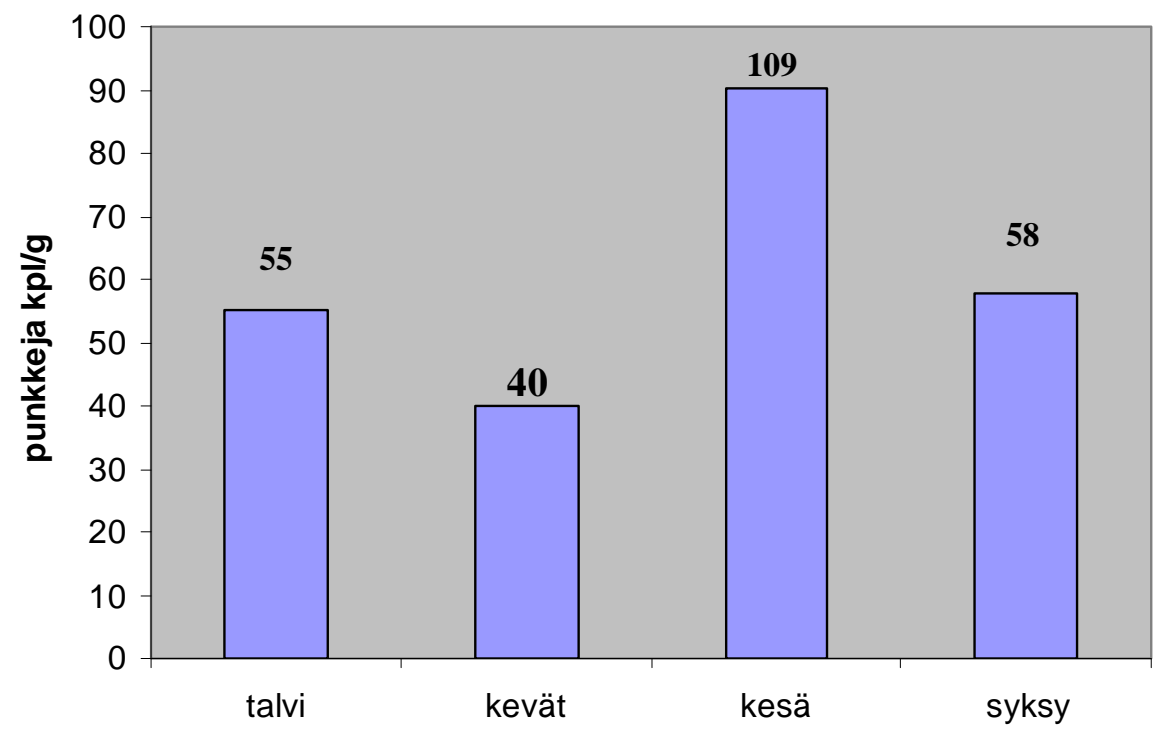

Kuva 1. Punkkimäärien mediaanit vuodenajoittain. Kaikki näytteet huomioitu.

Kuvassa 2 on eritelty näytteet ryhmiin koti, työvaatetus ja eläintila. Punkkipitoisuudet työvaatetuksessa ja kodeissa olivat lähes yhtä suuret, mutta selkeästi pienemmät kuin eläintiloissa. Kodeista ja työvaatetuksesta löytyi eniten punkkeja kesällä, määrien jäädessä kuitenkin keskimäärin alle sadan kappaleen grammassa. Ero pienimpään eli kevään tulokseen kotien välillä oli 4,6-kertainen. Vuodenaikaisvaihtelu oli sama kuin mikä saatiin kaikki näytteet yhdistämällä, mutta ero oli suurempi. 
Eläintiloista taas punkkeja löytyi eniten talvella ja syksyllä. Ero syksyn ja kevään tuloksella oli 2,8kertainen. Kun verrattiin punkkimääriä lähinnä huonepölypunkeille arvioituun herkistymisrajaan (100 $\mathrm{kpl} / \mathrm{g}) \mathrm{ja}$ akuutin oireilun $(500 \mathrm{kpl} / \mathrm{g}$ ) raja-arvoon, voitiin todeta, että kesällä $47 \%$ :ssa näytteistä ylittyi $100 \mathrm{kpl} / \mathrm{g}$. Akuutin oireilun raja ylittyi maksimissaan $17 \%$ :ssa näytteistä syksyllä ja talvella. Vastaavasti kesällä 100-500 kpl/g määrät olivat yleisiä.

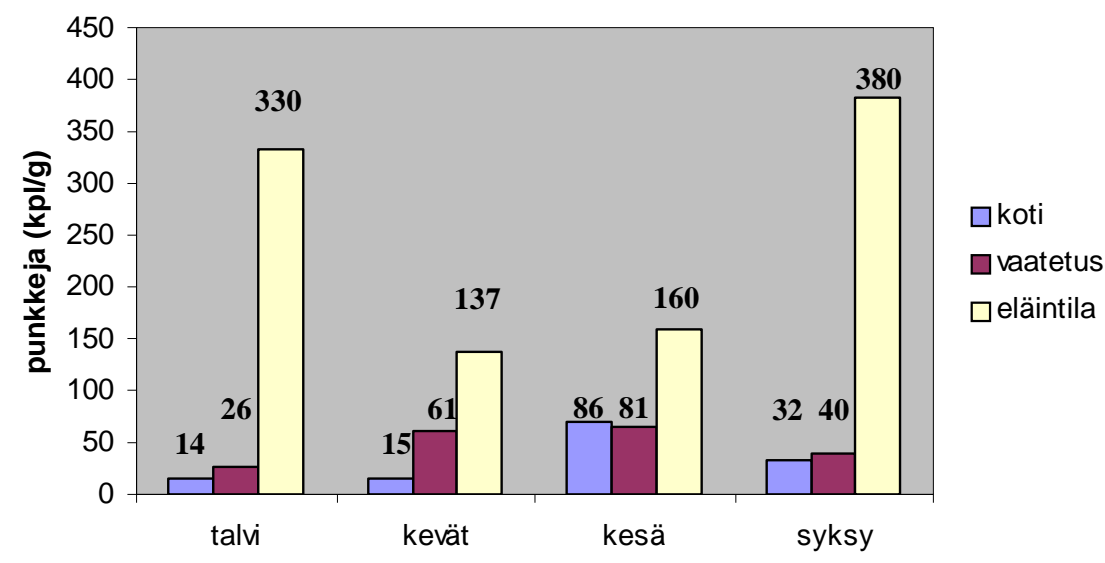

Kuva 2. Punkkimäärien mediaanit näytteenottokohteittain ja vuodenajoittain jaoteltuna.

Hajonnat näytteiden kesken olivat suuria, esimerkiksi ensimmäisellä kierroksella eläintilojen punkkipitoisuudet vaihtelivat $45 \mathrm{kpl} / \mathrm{g}-68000 \mathrm{kpl} / \mathrm{g}$. Kuvassa 3 on tarkasteltu vain eläintilanäytteitä sikaloista, kanaloista ja talleista erikseen. Kanaloista löytyi eniten punkkeja kaikkina vuodenaikoina ja talleista vähiten. Sikaloiden punkkimäärät jäivät näiden ääripäiden välille. Syksyllä punkkeja näyttäisi esiintyvän eniten kanaloissa (ero kesään 8-kertainen) ja talleissa (ero kevääseen 26-kertainen). Sikaloissa taas talvi on punkkirikkainta aikaa.

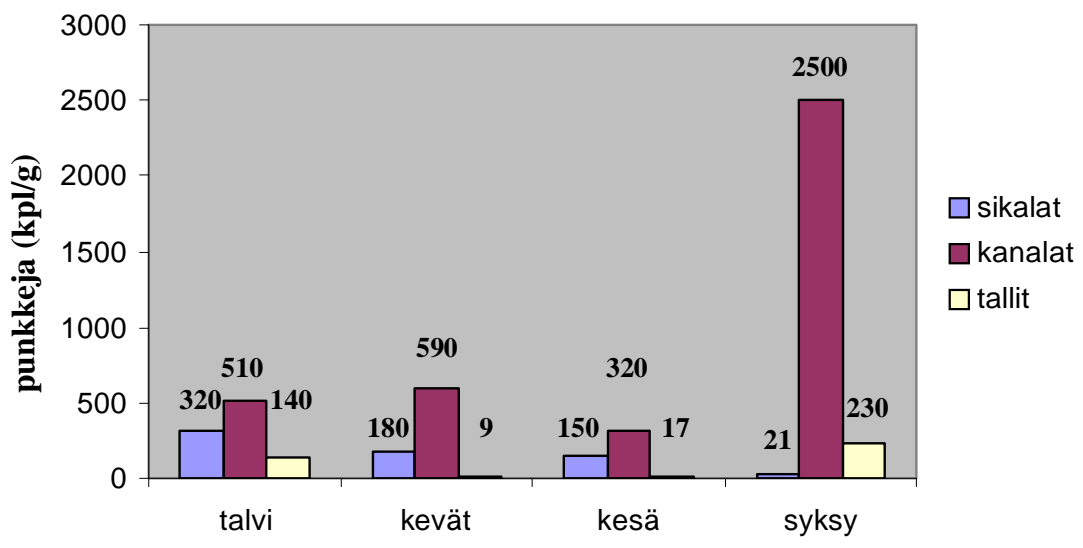

Kuva 3. Punkkimäärien mediaanit eläintilanäytteissä vuodenajoittain ja näytteen-ottokohteittain jaoteltuna.

Talvella ja keväällä runsain punkkiheimo oli Glycyphagidae, jota löytyi erityisesti kanaloista. Sen sijaan kesällä runsaimpana esiintyi Pyroglyphidae ja syksyllä Acaridae. Runsaimmat heimot kuuluvat kaikki Astigmata-lahkoon. Eri heimoista Acaridae punkit esiintyivät runsaimmillaan talvella ja syksyllä, Glycyphagidae keväällä, Mesostigmata ja Tarsonemidae kesällä. Pyroglyphidae -heimon punkit tuntuivat menestyvän hyvin kaikkina muina vuodenaikoina paitsi talvella. 
Kodeissa yleisiä punkkeja olivat odotetusti huonepölypunkit, mutta useista näytteistä löytyi myös Acaridae -heimon varastopunkkeja, joihin muun muassa Acarus siro ja Tyrophagus putrescentiae kuuluvat. Mesostigmata -lahkon punkkeja löytyi kodeista kaikkina vuodenaikoina pieniä määriä. Tarsonemidae -punkit olivat kodeissa selvästi yleisempiä kesäaikaan (61\% näytteistä) kuin muina vuodenaikoina.

Tarsonemidae -heimon varastopunkit, joista tunnetuin lienee Tarsonemus sp. olivat yleisiä myös työvaatetuksessa. Toinen hallitseva punkkiheimo työvaatetuksessa oli Acaridae. Työvaatetuksen punkeissa ei ollut havaittavissa selvää vuodenaikaisvaihtelua. Kuitenkin Tydeidae, Mesostigmata ja Eriophyoidea punkkeja löytyi vain kesällä.

Eläintiloista löytyi yleisimmin Astigmata -lahkoon kuuluvia Acaridae, Pyroglyphidae (huonepölypunkit) ja Glycyphagidae heimojen punkkeja sekä Prostigmata -lahkoon kuuluvia Cheyletidae (petopunkit) ja Tarsonemidae heimojen punkkeja. Myös Mesostigmata -lahkon punkkeja, joihin muun muassa Dermanyssus gallinae (kanapunkki) kuuluu, löytyi kaikkina vuodenaikoina. Tarsonemidae -punkkeja löytyi eläintiloista useimmin talvella (50 \% näytteistä) ja syksyllä (42\%). Kesä oli kaikissa näyteryhmissä (koti, työvaatetus ja eläintila) kaikkein heterogeenisimmän lajiston aikaa eli lajisto oli rikkaimmillaan. Pygmephoridae ja Erythraeidae punkkeja löytyi eläintiloista vain kesällä.

Punkkien kulkeutumista maatalouslomittajien mukana tutkittiin ottamalla näytteitä heidän työvaatetuksestaan, autoistaan ja kodeistaan. Lomittajat työskentelivät sikaloiden, kanaloiden ja tallien lisäksi nautakarja- ja lammastiloilla. Eniten punkkeja oli työvaatetuksessa. Acaridae oli yleisin punkkiheimo kaikissa kolmessa näytetyypissä.

Oirekyselyn perusteella lomittajat kärsivät iho-oireista enemmän kuin viljelijät. Tutkittujen sikaloiden ja kanaloiden työntekijät kärsivät hengitystieoireista enemmän kuin tallien työntekijät. Lääkärin toteamia allergiasairauksia oli yleensä viljelijöillä saman verran kuin väestössä keskimäärin ja lomittajilla hiukan tavanomaista enemmän. Lomittajista oli $17 \%$ herkistynyt ainakin yhdelle punkille.

\section{Tulosten tarkastelu}

Kaiken kaikkiaan eläintiloista löytyi aina eniten punkkeja. Kodeissa ja työvaatetuksessa oli kesällä suurimmat punkkimäärät, talven ja syksyn ollessa eläintiloissa punkkirikkainta aikaa. Vuodenaikaisvaihtelu riippui siis näytteenotto-ympäristöstä eli tässä tapauksessa siitä, oltiinko kodissa vai eläintilassa. Punkkimäärien vuodenaikaisvaihtelu kodeissa vastaa hyvin aikaisemmissa tutkimuksissa havaittua vaihtelua, minkä mukaan huippu punkkimäärissä saavutetaan korkeimpien lämpötila- ja kosteusolojen vallitessa. Kotioloissa kosteus ja lämpötila ovat kesällä yleensä talvea suuremmat, koska kesällä ovia ja ikkunoita pidetään enemmän auki, jolloin kostea ulkoilma pääsee leviämään sisätiloihin. Talvella taas ikkunat pidetään kiinni ja keskuslämmitys päällä, mikä luo punkeille epäsuotuisan, lämpimän, mutta kuivan ilmaston (Hart 1990). Eläintiloissa taas tilanne voi olla päinvastainen. Talvella eläimet ovat sisällä ja ovet pidetään kiinni, jolloin eläinten itsensä tuottama kosteus ja lämpötila saattavat nousta kesäaikaisia korkeammiksi. Kesällä varsinkin kivirakenteisissa eläintiloissa on usein ulkoilmaa viileämpää. Verrattaessa eri eläintiloja toisiinsa huomataan, että kanaloista ja talleista löytyi eniten punkkeja syksyllä ja sikaloista talvella. Tulos vastaa hyvin eläintiloissa yleisesti havaittua vuodenaikaisvaihtelua.

Lajiston runsauden vuodenaikaisvaihtelua on havaittavissa Acaridae -heimon punkeilla, jotka olivat runsaimmillaan syksyllä ja talvella. Tämä viittaa Acaridaen viihtymiseen erityisesti eläintiloissa. Mesostigmatalle ja Tarsonemidaelle kesä oli suotuisinta aikaa tuoden nämä punkit myös koteihin. Pyroglyphidae - heimon punkit menestyivät muina vuodenaikoina kuin talvella. Kodit olivat kesällä näille huonepölypunkeille suotuisa elinympäristö, mutta niitä tavattiin suurina määrinä myös kanaloista.

Kun tarkastellaan eri punkkiheimojen yleisyyttä näytteissä havaitaan Tarsonemidae -heimon yleisyydessä selvin vuodenaikaisvaihtelu. Heimo yleistyi kesäaikaan kodeissa, mutta talvella ja syksyllä eläintiloissa eli noudatteli samankaltaista vuodenaikaisvaihtelua kuin punkkimäärät. Tarsonemidae lienee kaikkein herkin lämpötila- ja kosteusmuutoksille. Lisäksi se pienenä punkkina kulkeutuu vaatteiden mukana helposti. Mahdollista siis on, että punkkeja siirtyy kesäksi eläintiloista koteihin ja talveksi takaisin eläintiloihin. Kesällä punkkilajisto oli monimuotoisin kaikissa 
näytteenottokohteissa. Esimerkiksi Pygmephoridae -heimon punkkeja löytyi näytteistä vain kesällä, joskin pieniä määriä. Kesä on otollisinta aikaa muidenkin hämähäkkieläinten lisääntymiselle.

Pidimme punkkien kulkeutumista kotiin todennäköisenä, jos samaa punkkiheimoa löytyi sekä kodista että eläintilasta. Sikaloista ja talleista kulkeutuivat yleisimmin Tarsonemidae ja Acaridae. Kanaloista näytti kulkeutuvan Tarsonemidaen ja Acaridaen lisäksi myös Pyroglyphidae -heimon punkkeja. Kesällä kuitenkin sekä kanaloista että niiden yhteydessä olevista asuinrakennuksista löytyi myös Mesostigmata ja Glycyphagidae punkkeja. Kesä lienee rikkaan punkkilajiston vuoksi myös parasta aikaa punkkien liikkumiselle. Talvella ulos kulkeutuneet punkit kuolevat pakkaseen. Tulokset osoittavat erityisesti Tarsonemidae ja Acaridae -heimojen punkkien kulkeutuvan tuotantotiloista asuntoihin työvaatteiden mukana. Vastaavia tuloksia on saatu myös aikaisemmissa suomalaistutkimuksissa (Heikkinen ym. 1990, Hanhela 1999), joissa varastopunkkien kulkeutumista navetoista asuinrakennuksiin pidettiin mahdollisena.

Maatalouden työympäristöistä löytyi runsaasti punkkeja, kuten oli odotettavissa. Tulokset ovat kuitenkin täysin uusia. Karja- ja maitotilat, heinävarastot ja viljavarastot ovat jo kohtuullisen hyvin tutkittuja punkkien suhteen, jopa Suomessa (Leskinen \& Kärenlampi 1981, Terho et al. 1982, Klen \& Leskinen 1985, Leskinen \& Klen 1987, Hanhela 1999). Muista tilatyypeistä, kuten nyt kyseessä olevista sikaloista, kanaloista ja talleista, on vain muutamia julkaistuja raportteja, ja nekin ulkomailta (Brady 1970, Solarz ym. 1997).

Punkkimäärät eri tilatyypeissä vähenivät järjestyksessä kanalat > sikalat > tallit. Kanaloiden runsaat punkkimäärät olivat yllätys. Aikaisemmissa tutkimuksissa (Brady 1970, Solarz ym. 1997) kanaloista löytyi punkkeja kohtalaisen runsaasti, mutta ei kuitenkaan nyt havaittuja määriä. Tuotantoeläimen koon suurentuessa punkkimäärät vähenivät. Tämä on todennäköisesti seurausta sekä ilman kosteuden ja lämpötilan laskemisesta että tilojen pölyisyyden vähenemisestä. Samoin erot siivoustiheydessä (talleissa siivotaan ainakin jossain määrin päivittäin) voivat olla vaikuttamassa punkkimäärien vaihteluun. Toisaalta runsas heinän ja kuivikkeiden käyttö voi talleilla lisätä punkkien määrää. Sikaloiden ja tallien lajisto oli hyvin saman tapainen kuin navetoiden ja heinävarastojen lajisto. Yleisimpiä ja runsaimpia punkkeja olivat sukujen Acarus (Acaridae) ja Lepidoglyphus (Glycyphagidae) punkit. Lajisto kanaloissa oli jossain määrin samanlaista kuin aikaisemmissa tutkimuksissa, mutta selkeänä erona oli meiltä löytyneet suuret määrät Pyroglyphidae ja Glycyphagidae heimojen punkkeja. Eron voi osittain aiheuttaa erilainen näytteenottoympäristö, koska esimerkiksi Bradyn (1970) työssä tutkittiin lattiakanaloita. Vaikka kaikissa tutkituissa kanaloissa oli koneellinen ilman vaihto, olosuhteet olivat silti lämpimät ja kosteat. Tämän lisäksi runsas ravinnosta ja kanoista itsestään kertyvä pöly on edesauttanut pitämään yllä runsaita punkkipopulaatioita.

Maataloden puolella tuotanto- tai varastotiloista löytyvät punkit ovat pääasiassa lähtöisin ulkoa (Hallas ja Iversen 1996). Suoraan pellolta tulevassa heinässä tai muussa materiaalissa on yleensä niukasti punkkeja (Hallas ja Gudmundsson 1985), mutta jo vuoden varastoinnin jälkeen esimerkiksi heinässä saattaa olla jopa 22000 punkkia kilossa (Hallas ja Gudmundsson 1985).

\section{Johtopäätökset}

Riski altistua ja herkistyä punkeille on ilmeinen maatalouden parissa, joten altistumisen ehkäisy on tärkeää. Kanala on tässä tutkimuksessa tutkituista kohteista pahin paikka punkkialtistumisen kannalta. Herkistymisraja-arvon ylittäville pitoisuuksille voi altistua kanaloiden lisäksi sikaloissa, talleissa ja kodeissa. Punkkien määrän voi minimoida tehokkalla siivouksella ja muuttamalla olosuhteet punkeille epäsuotuisaksi toisin sanoen pitämällä ilman lämpötila ja kosteus riittävän alhaisina. Riittävä ilmanvaihto ja oikeanlainen suojautuminen ovat tärkeitä keinoja altistumisen vähentämiseksi.

\section{Kirjallisuus}

Brady, J. 1970: The mites of poultry litter Observations on the bionomics of common species, with a species list for England and Wales. - J. Appl. Ecol. 7:331-348.

Cuthbert, O. D. 1990: Storage Mite allergy. - Clin. Rev. Allergy 8:69-86. 
van Hage-Hamsten, M., Johansson, S. G. O. ja Zetterstom, O. 1987: Predominance of mite allergy over allergy to pollens and animal danders in a farming population. - Clin. Allergy 17:417-423.

Hallas, T. E. ja Gudmundsson, B. 1985: Mites of stored hay in Iceland. Related to quality of hay and the storage duration. - J. Agr. Res. Icel. 17:31-37.

Hallas, E. ja Iversen, M. 1996: Sources of exporsure to storage mites in the farming environment. Ann. Agric. Environ. Med. 3:9-12.

Hanhela, R. 1999: Työolosuhteiden vaikutus ammattiastman syntyyn karjanhoitotyössä. Maatalousyrittäjien eläkelaitoksen julkaisut 1999.

Heikkinen, P., Leskinen, L., Kalliokoski, P., Terho, E. O., Tukiainen, H. ja Klen, T. 1990: Asuinhuoneistojen punkkifauna Suomessa ja varastopunkkien kulkeutuminen maatalouden työtiloista asuintiloihin. - Kuopion yliopiston ympäristötieteiden laitosten monistesarja, pp. 34.

Iversen, M. ja Hallas, T. E. 1995: Storage mite allergy in farming. - Ann. Agric. Environ. Med. 2:2730.

Klen, T. ja Leskinen, L. 1985: Navetan ja heinävaraston punkkien määritysmenetelmä. Työterveyslaitoksen tutkimuksia 3:405-418.

Kronqvist, M., Johansson E., Pershagen, G., Johansson S. G. O. ja van Hage-Hamsten, M. 1999: Increasing prevalence of asthma over 12 years among dairy farmers on Gotland, Sweden: storage mites remain dominant allergens. - Clin. Exp. Allergy 29:35-41.

Leskinen, L. ja Klen, T. 1987: Storage mites in the work environment of farmers. - Eur. J. Res. Dis. 71:101-111.

Leskinen, L., ja Kärenlampi, L. 1981: Pohjois-Savon navetoiden ja heinä-varastojen punkit. - Savon Luonto 13:41-50.

Müsken, H., Franz, J. T., Wahl, R., Paap, A., Cromwell, O., Masuch, G. ja Bergmann, K. C. 2000: Sensitization to different mite species in German farmers: Clinical aspects. - Invest. Allergol. Clin. Immunol. 10:346-351.

Platts-Mills, T. A. ja Chapman, M. D. 1987: Dust mites: Immunology, allergic disease and environmental control. - J. Allergy Clin. Immunol. 80:755-775.

Platts-Mills, T. A. E. ja de Weck, A. L. 1989: Dust mite allergens and asthma - A worldwide problem. - J. Allergy Clin. Immunol. 83:416-427.

Platts-Mills, T. A. E., Thomas, W. R., Aalberse, R. C., Vervloet, D. ja Chapman, M. D. 1992: Dust mite allergens and asthma: Report of a second international workshop. - J. Allergy Clin. Immunol. 89:1046-1060.

Platts-Mills, T. A., Vervloet, D., Thomas, W. R., Aalberse, R. C. ja Chapman, M. D. 1997: Indoor allergens and asthma: report of the third international workshop. - J. Allergy Clin. Immunol. 100:124.

Solarz, K. 1997: Seasonal dynamics of house dust mite populations in bed/mattress dust from two dwellings in Sosnowiec (Upper Silesia, Poland): an attempt to assess exposure. - Ann. Agric. Environ. Med. 4:253-261.

Terho, E. O., Leskinen, L., Husman, K. ja Kärenlampi, L. 1982: Occurence of storage mites in Finnish farming environments. - Allergy 37:15-19. 